\title{
NEWS AND NOTES
}

\section{SILVICULTURAL MEETING AT PETAWAWA}

F OLLOWING suggestions made by the Executive Council of the Wood7 lands Section, Canadian Pulp and Paper Association, a meeting to consider the needs of silvicultural research with regard to the management of pulpwood forests was held at the Petawawa Forest Experiment Station, May 25 and 26, Chalk River, Ontario. The meeting was under the joint chairmanship of Major-General Howard Kennedy, Vice-Chairman of the Woodlands Section, and Mr. D. Roy Cameron, Dominion Forester. Mr. A. Koroleff, Manager, Woodlands Section, Canadian Pulp and Paper Association, acted as secretary.

Among those who attended this meeting were the following: Messrs. Cameron, Kennedy, Koroleff, Cook, Johnston, Godwin, McCormack, Hierlily, Greig, Cosens, Delahay, Gibson, Pepler, Shaw, Bennett, Godden, Whitelaw, Harrison, Macdonald, Candy, Tunstell, Mulloy, Sonley, Gorman, Robertson, Lyons, Bonner, Miller, McElhanney, Hale, Minard, Mix, Morison, Noakes, James, Springer and Fensom.

The objectives of this meeting were to define the main needs of silvicultural research on behalf of pulpwood forests, to consider the facilities, and to outline a plan of action; and, in order that there might be some definite conclusions in respect to the points at issue, discussion on Friday, May 25, was more or less confined to the following specific items:

(a) Choice of species as to desirability for industrial use.

(b) Silvicultural characteristics of chief species from germination to maturity.

(c) Control of forest regeneration through choice of harvest cutting (what is silviculturally desirable cutting in typical cases; and how to reconcile this, when required, with the maximum in logging economy).

(d) Commercial possibilities of artificial regeneration.

(e) Practical means for increasing growth rate of desirable species.

(f) Treatment of slash.

(g) Means for decrease of forest vulnerability through silviculture.

There was considerable discussion on item (a), especially in respect to the feasibility or otherwise of establishing tentative indices indicative of the ultimate commercial value of each species. No suggestions were made in this connection as it was thought that there were too many unknown factors which would need to be carefully and analytically studied before any useful evaluation could be made.

The major part of this discussion had reference to the comparative value of spruce and balsam for pulpwood, having in mind all relevant factors such as susceptibility to disease, period of rotation, yield per acre in pulp fibre, marketability, possible conversion of manufacturing practices, and so on. 
It was concluded that no species can be written off as a total loss, no matter what difficulties are involved in regeneration, management, and manufacture. The weed tree of to-day may be the breadwinner of to-morrow, and this possibility should be accepted as a major principle in all silvicultural planning irrespective of existing preferences, prejudices and conditions.

Mr.W. M. (Bill) Robertson opened the discussion on item (b) by summarizing silvicultural methods and progress in Canada. His remarks were as below:-

"This meeting has been called to discuss and exchange views on the value and application of silvicultural cutting methods in pulpwood forests. We want to review what has been accomplished, what should be undertaken, and how the work can be prosecuted to the best advantage to all concerned.

"Our first problem is to plan investigations of cutting methods to improve increment and reproduction. This is the direct concern of the Silviculturist. But silviculture must be economically practical. The second stage then is to correlate silviculture with economics, including operations and protection. The effect of treatment on immediate and future returns must be considered. The possibility of modifying economic costs to meet silvicultural requirements should be investigated.

"Research in this field is the responsibility of the operator. Although our primary concern is with silviculture, research in the two fields should be conducted simultaneously. For this reason, then, the investigations should be conducted as large scale co-operative experiments.

"Perhaps because of lack of appreciation on the part of those in control of operations of the significance of silviculture as a means of converting a mining proposition to one of profitable sustained yield, no thought has been given to the practice of silviculture. While these exploitation methods have provided supplies of cheap, accessible wood from nature's store, immature stands at the age of highest volume production have been sacrificed. Not infrequently trees removed are too small even to be economically profitable. No consideration is given to the future of the stand depending entirely upon regeneration, nor to the effect of exposure upon soil deterioration.

"The only remedy unless better cutting practices are adopted is closer utilization of stands presently considered to be inaccessible and by-passed, or going farther afield. These remedies can only be temporary stop-gaps and spell higher cost wood.

"It behooves us, as foresters, to demonstrate to the controllers by factual data that better silviculture is the answer to the problem. Such demonstrations can only be made by large scale empirical research, by experimental cutting areas conducted on a co-operative basis.

\section{Silvicultural Methods}

"Empirical, or trial-and-error methods will tell us what results may be expected from a given method of treatment. It is no less important to learn why these results obtain if intelligent adjustments are to be made. For 
example, we know from empirical research that spruce sometimes regenerates after fire, but fails after cutting. Until we know why these conditions prevail, corrective measures are impossible. Hence fundamental research, the prerogative of the research organization, should be carried on simultaneously with empirical research.

"Preliminary to a report on what has been accomplished, it might be well to enumerate the various recognized cutting methods. For a description of them $m_{1}$ and their application, I would refer you to R. C. Hawley's publication, "Practice of Silviculture" or to our Research Note No. 74, Observations on Silvicultural Cutting Methods.

"Silvicultural Cutting Methods may be divided into two classes:

I Harvest Cuttings, or final cuttings-where the mature crop is being removed, and

II Intermediate Cuttings, principally thinnings and improvement cuttings, made in a stand before it is mature.

Of the harvest cuttings there are two classes:

A-Reproduction Cuttings, when the purpose is to reproduce the same species;

$\mathrm{B}$-Succession Cuttings, when certain species are being removed to release a stand of more desirable species. For instance, removal of poplar and white birch to release spruce and fir.

The four well recognized harvest cutting methods are:

1. Clear-cutting, 2. seed-tree, 3. shelterwood, 4. selection.

Various modifications of each of these standards are recognized.

"The term clear-cutting is rather a misnomer, and the accepted definition "removal of mature timber in one cut" should be kept in mind. Unfortunately present practice in Canada is to remove all merchantable timber with little or no regard to its maturity, and hence the method often involves serious loss of increment.

"By the shelterwood method the entire stand is remaved in two or three cuts, during which intervals reproduction is firmly established.

"Silviculturally the selection method is superior to any of the others. The system develops and maintains a well stocked stand of all age-classes. The harvest is mature timber; increment is maximum; mortality is minimum.

"Economically, however, the method in unmodified form is not practical in large-scale operations under present operating conditions. With development of permanent roads and improvements these objections will disappear to a large extent. In the meantime, a modification to cut on a 20 -year cycle may be a solution.

"Although intermediate cuttings should have a place in management plans, I will not take up your time to discuss them now.

What Has Been Done

"As has been shown in D.F.S. Bull. 90, "Growth and Regeneration Surveys", a good deal of information has been collected with respect to condi. 
tions following standard cutting methods. Much more data have been collected by other organizations, but these data have not yet been made accessible.

"A number of experimental cutting areas have been established by this Service in co-operation with the industry but for one reason or another they have not all received the protection they must have if they are to serve the purpose intended.

"The Bathurst Experimental Cutting area, 500 acres, was established in 1919 in a mature even-aged black spruce type. It was intended to study strip and group clear-cutting, and cutting to various diameter limits. The area was subsequently clear-cut. It was found, hawever, that mortality was high in the $10^{\prime \prime}$ and 12" diameter limit cutting. The 1937 remeasurements show that there is ample reproduction of spruce, much of it from layering. The growth rate is satisfactory. There were then sufficient spruce saplings $1^{\prime \prime}$ to $2^{\prime \prime}$ D.B.H. to provide the next crop. From what information was ob. tained it would seem that clear-cutting in this even-aged type is justified.

"A similar experiment in mixed-wood type in Newfoundland has resulted in almost pure fir regeneration in stands cut under 7" D.B.H. This cutting greatly stimulated growth.

"The Cains river area was established in 1922 to study the slaw-growing black spruce type. Although intended to be cut to 6 " and 8" diameter limits it was actually practically clear-cut. The 1937 remeasurements show that spruce regeneration was prolific-but differs from that at Bathurst in that the growth rate is very slow. The seedlings have grown less than five feet in the 15 -year interval. The site is probably not capable of producing another crop of trees $6 "$ to $8^{\prime \prime}$ D.B.H. within 100 years. The next remeasurement, due in 1947, should provide some reliable data on this factor.

"More information has been derived from the Salmon River Experimen. tal Cutting Area than from any others so far established.

"This area, 200 acres, established in co-operation with the Pejepscot Company in 1924, has been remeasured twice-in 1933 and in 1938.

"It is in a virgin and therefore overmature stand, the principal species being red spruce. As this species is long lived comparatively little of it is of the younger age classes.

"The area divided into four sections represents untreated stand, clearcut in strips, standard 12" diameter limit, and shelterwood, leaving from 25 to 60 per cent of the stand.

"Net annual increment and mortality 1924.38 varied from $29.0 \mathrm{cu}$. ft. on the control area to $52 \mathrm{cu}$. ft. on the 12 " diameter limit. Mortality varied from $11 \mathrm{cu}$. $\mathrm{ft}$. on the clear-cut to $117 \mathrm{cu}$. $\mathrm{ft}$. on the shelterwood area.

"Reproduction is ample everywhere and is about equally divided between spruce and fir. The best results were on the control and shelterwood cutting -the poorest on the 12" limit. Spruce is thrifty and of good growth. The fir is poor and already tending to disappear. 
"Advance growth has not responded satisfactorily, probably because it was too old before it was released.

"Conclusions are that on the whole the shelterwood method was the best for this type of stand. The procedure should be to select the overmature trees without regard to diameter class.

"The records indicate too that $5 \%$ sampling by line plots is not sufficient in an area as small as 200 acres. Sampling by transect plot is recommended

"The shelterwood portion of this stand was removed in 1939-the proper procedure since regeneration was established.

"Two experimental girdling areas of 50 acres each were established in the mixed-wood type at Salmon River in 1928. These were remeasured in 1933 and in 1938. The purpose was to release spruce and fir from suppres. sion of wolf hardwoods. The deductions are:-

"Spruce and fir are ample for future needs.

"Girdling increased growth of spruce from 88 cubic feet to 115 cubic feet on one area, and from 33 cubic feet to 58 cubic feet on the second area.

"There are sufficient seedlings on one area and a cutting is recommended. Reproduction is not sufficient on the second area yet and cutting should be postponed for at least ten years.

"Hardwood competition at Lake Edward retarded growth of spruce and fir for 20 years but when these species entered the upper crown the growth rate was stimulated to $50^{\circ}$ cubic feet per yearacre. Regeneration is fair.

"The Carrot River Experimental Cutting Area, Saskatchewan, shows that regeneration is a serious problem there. None of the various cutting methods tried have resulted in satisfactory reproduction. The mineral soil must be exposed.

"A series of 12 small experimental cutting areas have been established at Petawawa since the Pulpwood meeting held here in 1935. This project was undertaken at the instigation of members of your Association. Unfortunately, however, the pulpwood types are not well represented here.

"The experiments cover three site-types. Some of these experiments represent partial cutting, some the standard clear-cutting methods.

"It is proposed to visit some of the experiments. However, sufficient time has not elapsed to provide information on anything but regeneration and mortality.

"The foregoing is a brief summary of what has been accomplished in the problem of experimental cutting areas in pulpwood species.

\section{What Should Be Done}

"It is very evident that this important project is not receiving the attention it deserves.

"This Service and Provincial Services should have Research Stations or at least Research Experimental Areas in each of the pulpwood forest sections where fundamental as well as empirical methods should be studied ag. gressively. 
"Simultaneously large scale experimental cutting areas should be under. taken in co-operation with the operators. These areas should represent mixedwood as well as softwood cover types and site-types, and the various cutting methods which suggest that some degree of success may be attained. Although major importance should be placed on harvest cuttings, some consideration should also be given to intermediate cuttings.

\section{Clearing-House}

"Before closing I would like to refer again to the need for a clearing. house. If orderly procedure is to be followed where a number of organiza. tions are co-operating, if waste effort is to be avoided, if proper publicity is to be given to results attained, a central control organization representing all participants must be established. I trust that some consideration will be given to this problem at this meeting."

The idea of establishing a central clearing house for silvicultural infor. mation was enthusiastically received, and after a number had expressed their opinions in this connection it was agreed that the Dominion Forest Service would be the logical body to initiate this undertaking.

Mr. R. H. Candy, speaking on behalf of the Dominion Forest Service, then presented tentative plans for silvicultural research. These plans are outlined below under I-Regeneration and Growth of Canadian Forests; and II-Study of Regeneration under Disturbed Stands.

\section{Regeneration and Growth of Canadian Forests}

"Foresters have recognized for many years that the main difficulty in preparing plans for the management of our forest resources on a sustained yield basis is a lack of information on -

(1) The rate of growth of merchantable species, particularly in our disturbed stands.

(2) The extent to which these disturbed stands reproduce themselves to desirable species and particularly the length of time needed to regenerate them under present cutting methods.

"It is important to have more information on the above problems so that industry and responsible government forest services may be enabled to decide on silvicultural practice necessary to ensure sustained yield in our Canadian forests.

"Officials of the Dominion Forest Service have noted, more particularly in recent years, an ever increasing demand for information on rate of growth and estimate of regeneration of the more valuable species in our accessible forest areas, and consider that the study of this problem should be given a place of first importance in the post-war period.

"Based on information and experience gained in past years, and taking ad. vantage of studies on rate of growth and regeneration undertaken by other forest services on the North American continent, we have come to realize that the problem is an extremely diffcult one. Our forests are not only very extensive but are of many species, age-classes, density classes and site-types. 
In addition, they have been subjected to various methods and degrees of cutting, damage by fire, and insect attack.

"With the future prospects of a return to more normal conditions of staff and manpower following the end of the European war, we consider this problem should be given top priority consideration. On the basis of past experience in collecting growth data, we have reached the following conclusions:

(1) The most reliable information on the rate of growth in our various cover and site types and age-classes can only be obtained from periodic measurement of carefully selected permanent sample plots.

(2) While information can be made available much more rapidly from a single examination survey, it is likely to be less reliable. In addition, the best practical method of gathering information from such a single examination has yet to be determined.

(3) The gathering of information on regeneration of desirable species on disturbed stands, so urgently needed, can, it is believed, be fairly accurately obtained from a single examination by use of small mobile two-man parties.

"We believe that the study of growth should be divided into two phases. First, determination of growth and regeneration immediately and as accurately as possible by single examination of temporary sample plots. Second, determination of growth and regeneration more accurately by the slower method of remeasurement of these temporary samples, and of a series of permanent sample plots. These phases may be termed short and long range plans.

"For the short range plan, three methods of computation of increment should be considered. These are:-

(a) Mean annual increment (volume over age).

(b) Increment core.

(c) Stand density yield tables.

Final decision on the relative merits of each of these methods can be deferred until considerable data become available.

"Data on regeneration may also be collected on the same samples.

"For the long range plan the temporary samples may be used provided that their location is marked so that they may be remeasured at periodic intervals.

"For more reliable information, however, it is recommended that a large series of permanent sample plots be established. From all these plots then the increment may be determined by the resurvey method.

"In addition to these studies directly concerned with growth, a more extensive single examination survey of regeneration conditions should be made. This phase of the problem can be accomplished by mobile two-man parties making examination of cut-over and burned-over areas.

"Selection of areas to be surveyed should be based on Halliday's classification of forest regions and on information obtained from aerial photographs and from the forest industry. 
"It is believed that inauguration of the proposed studies should be the responsibility of governments, federal and provincial. But the field is large and there may be practical limits to the amount of work that can be done by governments in any one region. Should a specific unit of industry desire more plots than the government programs provide, it could easily establish them itself. Such work should be done in accordance with the outlines of procedure adopted, in order that results may be fitted into the general scheme. To be of maximum value methods followed must be in accordance with an approved standard, both in the method of collecting data and in compiling them.

"It is suggested that solution of the questions under consideration will require three different surveys, to be carried out concurrently in different parts of Canada, namely:-

(1) Extensive single examination survey to study regeneration exclusively;

(2) Less extensive semi-permanent transect or line'plot survey to measure increment as well as regeneration;

(3) Intensive permanent sample plot data which will commence to give reliable information after ten years.

"It must be clearly understood that the proposals set out in this paper represent the views of the Dominion Forest Service as to what should be done; but they do not constitute an announcement of a program which the Service is at present in a position to undertake. Before the work can get under way funds must be provided, additional personnel secured, and a number of complex questions respecting technique and procedure settled. In particular, details respecting co-operation of Dominion and Provincial authorities and the industry will require further study.

\section{Study of Regeneration Under Disturbed Stands}

"It is generally agreed that the first requisite for our future stands is adequate reproduction of desirable species. The first problem then is to make an inventory of regeneration on cut-over lands.

"Many regeneration surveys have been made from time to time during the past twenty-five years, but these have been sporadic and lack proper co-ordination. In consequence we still cannot say whether regeneration is satisfactory for any given cover-type, site-type, and cutting method.

"It is time that a comprehensive Canada-wide regeneration survey be launched.

"In our opinion such survey should be divided into three phases:

(1) General Reconnaissance, a rapid enumeration survey to determine what the conditions are on each of various cover-types, site-types, and cutting methods.

(2) An intensive study to determine why regeneration fails or is inadequate.

(3) Experimental cuttings to correct the factors of failure. 


\section{General Reconnaissance}

"All that is required for this survey is a count and record of distribution of seedlings found under each of the conditions concerned. A large number of single examination samples to provide a reliable average must be taken. Adequate data can be collected by a two-man party.

"Since it usually requires at least five years for establishment of regeneration, no studies should be made on areas disturbed within a period of five years. The following procedure is suggested based on a two-man party.

Preliminary to Field Work

1. Determine the date or dates when area to be studied was logged or burned.

2. Determine amount and species of timber removed, the original cover type, and logging method employed.

3. Obtain a large-scale map of area and type map, if possible.

$$
\text { Field Work }
$$

1. From a suitable point, start a series of transect strips across area to be sampled. These strips should run at right angles to contour and their location shown on map. The distance between strips should depend on size of area to be studied (5, 10, or 20 chains).

2. Strip to be 3.3 feet wide, divided into units for separate tally, two chains long.

3. The tape will form the only boundary necessary to the narrow plot. A stick 3.3 feet long is all that is necessary to ensure width of strip.

4. A separate tally on each 2 -chain unit must be made of all merchantable species up to 1 -inch D.B.H. Unless there is very uneven distribution, it is only necessary to know whether or not there is ample regeneration for restocking purposes. Therefore, it is not necessary to count beyond 100 seedlings of each species per unit, a record of $100+$ should suffice. If distribution is very uneven, such as dense regeneration on logging road or some artificial disturbance, it should be noted in remarks.

5. All regeneration must be tallied in height classes

(a) $\mathrm{Up}_{\mathrm{p}}$ to $0.5 \mathrm{ft}$.

(b) 0.5 to $3.0 \mathrm{ft}$.

(c) Over $3.0 \mathrm{ft}$.

and sufficient study made to determine average age in each of three classes.

6. Any artificial disturbance such as roads, trails, etc. should be shown on the map.

7. Condition of reproduction should be classified as vigorous, fair, suppressed, or dying.

\section{Ocular Estimate of Other Factors}

"This should be done by tick-off method on back of form and should record the following ocular information for each unit:-

A. General condition of litter, humus and surface soil. 
B. Species and density of underbrush-scattered (not likely to interfere with regeneration); moderate (likely to interfere with regeneration: to some extent); and dense, (likely to interfere greatly with regeneration).

C. Approximate number and species of seed trees within 2 chains of each unit.

D. Crown density (whether $25,50,75$ or 100 per cent of complete cover).

E. Standing timber on area at date of survey, and its condition of health (defective, healthy, etc.)

F. Approximate age of trees in residual stand.

"Although it might appear that much information other than regeneration count is called for, actually this can be ticked off on the sheet in a few minutes.

\section{Intensive Study}

"After sufficient returns from the general reconnaissance are in to indicate where failures occur, an intensive study should be started to determine the fundamental silvicultural requirements of species involved in the failure.

"These factors are likely to be seed supply, seed bed conditions, and/or light requirements.

"This intensive survey need not be extensive within any forest section since a few samples in each condition should reveal the factors sought. Methods of approach should be worked out with the investigator responsible for the project.

\section{Experimental Cuttings}

"When the vital factors have thus been determined, they should be tested on a relatively small number of experimental cutting areas. Cutting areas established for other purposes, i.e. stimulation of growth, and resultant mortality might also be used for this project.

"These suggestions are offered at this time to obtain the reaction of the members here on the need for the investigation, and on the general approach to the problem. If they be approved details of ways and means should be worked out by a committee."

Mr. Candy's suggestions were favourably discussed, and Mr: D. Roy Cameron underlined the position of the Dominion Forest Service in desiring the reactions, comments, suggestions and support of the industry in respect to these proposals. He hoped, therefore, that they would be studied carefully by industry.

Speaking further on this item $M r . J . D$. B. Harrison commented on certain phases of the regeneration period, illustrating the points which he raised by means of charts. These points were:

1. The chief object of the practice of silviculture is the production of more wood per acre in a given period of time.

2. The word "silviculture" conveys to the mind a variety of procedures, some of which may be practicable under a given set of plyysical and economic conditions while others are not. For example, it may be quite possible to operate a farm woodlot in a densely settled region in Eastern Canada on the basis of individual tree selection, cutting over the whole area each year; but 
it is obviously impossible to operate the extensive holdings of a large pulp and paper company in that way. At the same time there may well be silvicultural procedures which are applicable now to pulp and paper operations and it is our object to attempt to identify their kind and develop their detail.

3. The obvious first step in introducing silviculture to logging operations is to ensure regeneration of the right kind and in the shortest possible time. If we reduce the regeneration period we alsa reduce the effective rotation.

4. There seem to be very considerable differences of opinion as to whether or not regeneration of spruce and balsam can be considered satisfactory in Eastern Canada. It is suggested that these differences occur because insuffcient attention is given to the length of the regeneration period. It is possible that satisfactory re-establishment of the desired species on cut-over areas usually takes place but that it comes in far too slowly. If it takes twenty-five years for Nature to plant up cut-overs on a site where some change in logging methods might result in re-establishment of the forest in five years, we can correctly say that the owner or holder of the land has lost the benefit of its productivity for twenty years.

5. If measurement of growing trees indicates that a satisfactory rotation age for pulpwood is sixty-five years and it takes five years to re-establish the stand, the effective rotation period is seventy years. If re-establishment takes twenty-five years, the effective rotation is ninety years.

6. If the effective rotation is ninety years instead of seventy years then the increase in time required to produce a crop is twenty-nine per cent. Obviously, reduction of regeneration period will of itself cause a substantial increase in the yield of the forest.

7. If there is any investment in the property then the financial effects of an unduly long regeneration period are far more serious. If there is an investment of $\$ 1.00$ per acre and the assumed rate of interest is $3 \%$, the investment per acre will rise from $\$ 7.92$ in seventy years to $\$ 14.30$ in ninety years, or an increase of $81 \%$.

8. The apparently trifling charges per acre for carrying Crown land when ground rental is $\$ 5.00$ per square mile and fire protection tax is $\$ 6.40$ per square mile, amount to $1.8 \mathrm{c}$ per acre. The accumulated value of these pay. ments is $\$ 4.15$ in seventy years and $\$ 7.98$ in ninety years, a difference of \$3.83. There are, of course, other charges incidental to carrying land, such as additional fire protection, surveys and so forth, which would substantially increase the figures used here.

9. It is evident that the benefits to be obtained from reduction of the regeneration period are important in terms of production per acre and even more important from the financial point of view. The interest rate used in the above calculations is low and the effects of the longer effective rotation period would be proportionally much greater if a higher interest rate were applied. 
It was indicated that selective cutting has not been much favoured by the pulpwood industry as a standard method of extraction, but it was admitted that data as to the effectiveness of such cutting is too meagre to justify its definite condemnation under any and all conditions.

"Layering" had its usual prominent place in the discussion, with no definite conclusions arrived at as to the certain causes of growth.

A resolutions committee consisting of Messrs. Shaw, Chairman; McCormack; Gibson; Cosens; Godwin and Macdonald was appointed; and at the conclusion of the discussion the following resolutions were presented to the meeting and unanimously adopted:-

I. Whereas it is recognized by the forest industry and Governments that there is an urgent and definite need for fundamental and factual data on regeneration on cut-over areas and rate of growth surveys, and whereas such information is essential to the perpetuation of Canada's forest resources, be it therefore resolved that a Joint Committee be set up, consisting of representatives from the forest industry, Provincial and Dominion Government Forest Services, with a view to finding ways and means of implementing the proposals with respect to surveys as outlined in the papers presented by the Dominion Forest Service at this meeting.

II. Whereas experimental work is necessary in our pulpwood forests to study methods for increasing the growth rate of desirable species, be it resolved that experimental areas be established for such purposes.

III. Whereas it is essential to collect and review all available data pertaining to Canada's forests and tree species, preparatory to conduct of further research and to the application of forest management practices, be it therefore resolved that the Woodlands Section consider recommending to the Dominion Forest Service that the Dominion Forest Service undertake the collection and review of such data, its publication and dissemination.

On Saturday, May 26th, under the able direction of Mr. Morison, Supervisor of the Station, the party was escorted to different sample plots. Among the different projects described by Messrs. Morison, Robertson, Mulloy, Macdonald and others during this tour were:

1. Experimental cutting of black spruce cover type.

2. Debudding experiments.

3. Succession cutting in pine.

4. Selection cutting in pine.

5. Strip cutting.

6. Splintwood and pulpwood cutting in jack pine.

7. Tree breeding.

8. Woodlot management.

In a red pine plantation all lateral buds are being pinched off annually except from the lowest three whorls and this will be continued until the tree is $20^{\prime}$ tall. Thereafter the crowns will be left to develop normally. The purpose is to produce one log of knot-free lumber. 
So far the treatment has had the effect of stimulating both height and diameter growth. The average growth for the past four years was 2.1 feet on treated trees, and $1.1^{\prime}$ on untreated trees. This "banana" tree or "up-side down" tree experiment is interesting, even amusing, but seems to have important possibilities.

Attention was drawn to three red and white pine plots in stands 40 years old when the plots were established in 1918. One plot was thinned three times; and one was thinned twice and cut for reproduction in 1941.

Control plot (P.S.P. 2) (All values per acre)

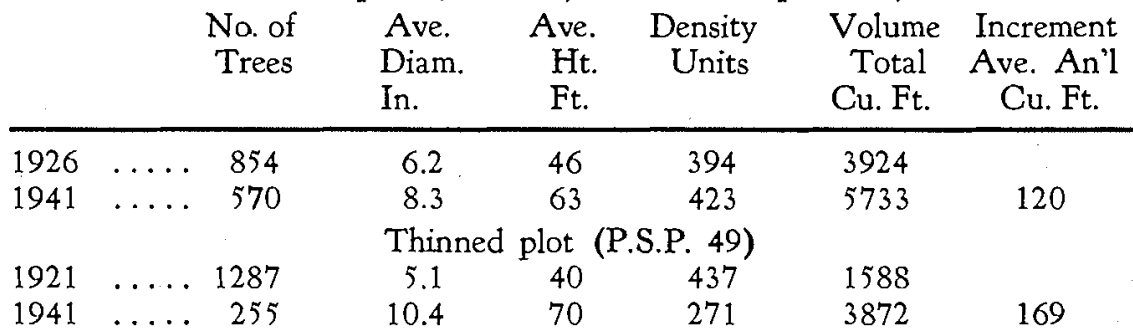

Increment is exclusive of thinnings which yielded:

$659+963+854$ or 2476 cu. ft.

Thinned and reproduction cut plot (P.S.P.) (1)

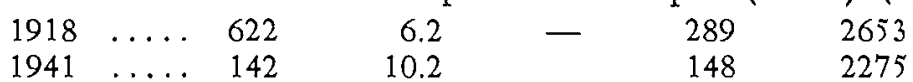

Intermediate cuttings were:

$540+1093+1382$ or 2915 cu. ft.

White pine reproduction is abundant and thriving, and a final harvest cutting will soon be made. Board foot values are also available.

Reference was made to a series of three sample plots in mixed spruce and pine growing on a first class site-type.

These plots were thinned once in 1921.

P.S.P. 51-75 per cent spruce and balsam, 25 per cent pine.

\begin{tabular}{|c|c|c|c|c|c|c|}
\hline & $\begin{array}{l}\text { No. of } \\
\text { Trees }\end{array}$ & $\begin{array}{l}\text { Ave. } \\
\text { Diam. } \\
\text { In. }\end{array}$ & $\begin{array}{c}\text { Ave. } \\
\text { Ht. } \\
\text { Ft. }\end{array}$ & $\begin{array}{c}\text { Density } \\
\text { Units }\end{array}$ & $\begin{array}{l}\text { Total } \\
\text { Volume } \\
\text { Cu. Ft. }\end{array}$ & $\begin{array}{c}\text { Ave. An'l } \\
\text { Increment } \\
\text { Cu. Ft. }\end{array}$ \\
\hline & 1100 & 5.4 & 46 & 459 & 3853 & \\
\hline
\end{tabular}

Thinnings 1921 yielded $107 \mathrm{cu}$. ft.

P.S.P. $52-30$ per cent spruce and balsam, 70 per cent pine

$\begin{array}{llllllll}1921 & \ldots & \ldots & 993 & 5.8 & - & 414 & 4097\end{array}$

$\begin{array}{lllllll}1941 & \ldots & 372 & 9.4 & 69 & 336 & 5491\end{array}$

Thinnings 1921 yielded $845 \mathrm{cu} \mathrm{ft}$. 
FORESTRY CHRONICLE

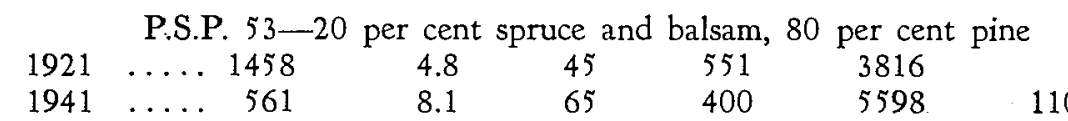

Thinnings 1921 yielded $423 \mathrm{cu}$. ft.

Another project observed was a cutting of mature jack pine just completed to release an understory of white and red pine and some small jack pine. Some 5,000 board feet per acre was removed and has left the stand about half stocked. There are ample white pine seedlings already germinated, and there is reason to believe that these will thrive under the light conditions created by the cutting.

A stand was visited from which all merchantable jack pine was removed two years ago. Slash was burned. Tops were removed for fuelwood.

Some red and white pine advance growth is present. However, as a result of at least four fires the soil is poor for these species.

Small experimental plantings of four species of hard pine have been made this spring. There was an adjoining area clear-cut but on which slash was left as it fell. The cutting is 5 years old, and slash is now pretty well decomposed.

As a supplementary study an area was clearcut last year from which the slash was lopped and scattered.

It has already been found that jack pine slash releases its cones when the slash lies within one foot of the ground. No regeneration counts have yet been made.

Along the Petawawa river there was a mixed-wood stand from which poplar and white birch was removed for match stock, pulpwood, and fuelwood. The operation was profitable and has left an excellent stand of pure white and red pine, the increment of which should be greatly stimulated by the treatment.

The last project visited was a partial cutting, and a strip cutting in mixed pines. In the partial cuttings, made in 1935, the stand was reduced variously to $80 \%, 40 \%$, and $20 \%$ density. It was shown that white pine reproduction was prolific on the stands cut to less than 80 per cent density and survival and growth of white pine seedlings promises to be satisfactory. Data from the representative sample plots are available.

After noting the advanced state of research on this station members of the industry were more than ever of the opinion that similar stations should be established in typical pulpwood areas. It was also the general opinion that the meeting as a whole had served a most useful purpose, that it had indicated some of the many gaps in silvicultural research, that it could not have been held in more enjoyable surroundings nor under better weather conditions, and that those in charge of arrangements had done an excellent job in every respect. 